\title{
The SspA subtilisin-like protease of Streptococcus suis triggers a pro-inflammatory response in macrophages through a non-proteolytic mechanism
}

\author{
Laetitia Bonifait ${ }^{1,2}$, Daniel Grenier ${ }^{1,2^{*}}$
}

\begin{abstract}
Background: Streptococcus suis is a major swine pathogen worldwide that causes meningitis, septicemia, arthritis, and endocarditis. Using animal models, a surface-associated subtilisin-like protease (SspA) has recently been shown to be an important virulence factor for S. suis. In this study, we hypothesized that the S. suis SspA subtilisin-like protease may modulate cytokine secretion by macrophages thus contributing to the pathogenic process of meningitis.

Results: Phorbol 12-myristate 13-acetate-differentiated U937 macrophages were stimulated with recombinant SspA prior to monitor cytokine secretion by ELISA. Our results indicated that the recombinant SspA was able to dosedependently induce IL-1 $\beta, I L-6, T N F-\alpha, C X C L 8$ and CCL5 secretion in macrophages. The heat-inactivated protease was still able to induce cytokine secretion suggesting a non-proteolytic mechanism of macrophage activation. Using specific kinase inhibitors, evidence were bought that cytokine secretion by macrophages stimulated with the recombinant SspA involves the mitogen-activated protein kinase signal transduction pathway. While stimulation of macrophages with low concentrations of recombinant SspA was associated to secretion of high amounts of CCL5, the use of recombinant SspA at a high concentration resulted in low amounts of CCL5 detected in the conditioned medium. This was found to be associated with a proteolytic degradation of CCL5 by SspA. The ability of SspA to induce cytokine secretion in macrophages was confirmed using a mutant of S. suis deficient in SspA expression.
\end{abstract}

Conclusion: In conclusion, this study identified a new mechanism by which the S. suis SspA may promote central nervous system inflammation associated with meningitis.

\section{Background}

Streptococcus suis is a major swine pathogen worldwide that causes meningitis, septicemia, arthritis, and endocarditis [1]. S. suis infections in humans remain sporadic and affect mainly individuals in close contact with sick or carrier pigs or pig-derived products, typically pig farmers, veterinary personnel, abattoir workers, and butchers [2]. However, the important outbreak that occurred in China in 1998 and 2005 modified the world perspective regarding the threat of $S$. suis for humans

\footnotetext{
* Correspondence: daniel.grenier@greb.ulaval.ca

'Groupe de Recherche en Écologie Buccale (GREB), Faculté de médecine

dentaire, Université Laval, Quebec City, Quebec, Canada

Full list of author information is available at the end of the article
}

$[3,4]$. S. suis is transmitted via the respiratory route and colonizes the palatine tonsils of pigs. While 35 serotypes ( 1 to 34 and 1/2) have been identified, serotype 2 is considered the most frequently associated with pathology [5], although other serotypes are also the source of many infections [6-8].

Various potential virulence factors produced by $S$. suis have been identified, including a sialic acid-rich capsule [9], an hemolysin (suilysin) [10], adhesins [11,12], and proteolytic enzymes $[13,14]$. Our laboratory recently reported on the cloning of a $170 \mathrm{kDa}$ subtilisin-like protease (SspA) found on the cell surface of S. suis [15]. This protease was found to possesses a high protein cleavage specificity and can degrade the $A \alpha$ chain of fibrinogen thus preventing

\section{Biomed Central}


thrombin-mediated fibrin formation [15]. Using animal models and deficient-mutants, the surface-associated SspA was found to play a key role as virulence factor for S. suis $[16,17]$. However, the exact contribution of the SspA in the pathogenic process of $S$. suis infections has not been clearly defined.

To cause meningitis, S. suis must first cross the mucosal barrier, enter the bloodstream, resist to host defense mechanisms in the intravascular space, invade the blood-brain barrier, and then replicate in the subarachnoidal space [18]. Once the bacteria reach the bloodbrain barrier, the secretion of proinflammatory cytokines, by host cells may contribute to increasing the permeability of this barrier [18-20]. A number of studies have reported that $S$. suis can induce the secretion of high amounts of proinflammatory cytokines by host cells, including monocytes/macrophages [19-21]. This excessive production of proinflammatory cytokines has been suggested to play a key role in pathogenesis of both systemic and central nervous system infections and to contribute to the pathogenic processes of meningitis $[22,23]$. The aim of this study was to investigate the capacity of the S. suis SspA subtilisin-like protease to modulate cytokine secretion by macrophages.

\section{Methods}

\section{Strains and growth conditions}

S. suis P1/7 (serotype 2) as well as a SspA deficient mutant (G6G) were used in this study. Mutant G6G was selected from a mutant library constructed using the pTV408 temperature-sensitive suicide vector to deliver the Tn917 transposon into S. suis P1/7 via electroporation [16]. This mutant is unable to degrade the chromogenic substrate (N-succinyl-Ala-Ala-Pro-Phe- $p \mathrm{Na}$; Sigma-Aldrich Canada Ltd., Oakville, ON, CANADA) specific for subtilisin-like proteases and showed a single Tn917 insertion into the gene coding for the SSU0757 protein in the genome of S. suis P1/7 [16]. Bacteria were grown at $37^{\circ} \mathrm{C}$ in Todd Hewitt broth (THB; BBL Microbiology Systems, Cockeysville, MA, USA).

\section{Preparation of recombinant SspA of S. suis}

The subtilisin-like protease SspA of S. suis was cloned, purified, and characterized in a previous study [15]. Briefly, the SSU0757 gene encoding the SspA was amplified and a 4,798-bp DNA fragment was obtained. It was cloned into the expression plasmid $\mathrm{pBAD} / \mathrm{HisB}$ and then inserted into Escherichia coli to overproduce the protein. The recombinant protease was purified by chromatography procedures and showed a molecular weight of $170 \mathrm{kDa}$. Using a chromogenic Limulus amebocyte lysate assay (Associates of Cape Cod, Inc., East Falmouth, MA), the SspA preparation was found to contain less than $5 \mathrm{ng}$ endotoxin/ml.

\section{Cultivation of monocytes and preparation of macrophage-like cells}

The monoblastic leukemia cell line U937 (ATCC CRL1593.2; American Type Culture Collection, Manassas, VA, USA) was cultivated at $37^{\circ} \mathrm{C}$ in a $5 \% \mathrm{CO}_{2}$ atmosphere in RPMI-1640 medium (HyClone Laboratories, Logan, UT, USA) supplemented with $10 \%$ heat-inactivated fetal bovine serum (FBS; RPMI-FBS) and $100 \mu \mathrm{g} /$ $\mathrm{ml}$ penicillin-streptomycin. Monocytes $\left(2 \times 10^{5}\right.$ cells $\left./ \mathrm{ml}\right)$ were incubated in RPMI-FBS containing $10 \mathrm{ng} / \mathrm{ml}$ of phorbol 12-myristic 13-acetate (PMA) for $48 \mathrm{~h}$ to induce differentiation into adherent macrophage-like cells [24]. Following the PMA treatment, the medium was replaced with fresh medium and differentiated macrophages were incubated for an additional $24 \mathrm{~h}$ prior to use. Adherent macrophages were suspended in RPMI-FBS and centrifuged at $200 \times \mathrm{g}$ for $5 \mathrm{~min}$. The cells were washed, suspended at a density of $1 \times 10^{6}$ cells $/ \mathrm{ml}$ in RPMI supplemented with $1 \%$ heat-inactivated FBS and seeded in a 96 well-plate $\left(1 \times 10^{6}\right.$ cells/well/0.2 $\mathrm{ml}$ ) at $37^{\circ} \mathrm{C}$ in $5 \% \mathrm{CO}_{2}$ atmosphere for $2 \mathrm{~h}$ prior to treatments.

\section{Treatment of macrophages}

PMA-differentiated U937 macrophages were treated with recombinant SspA at concentrations ranging from 0.00033 to $33 \mu \mathrm{g} / \mathrm{ml}$. Stimulation was also performed using the recombinant $\mathrm{SspA}$ treated at $100^{\circ} \mathrm{C}$ for $30 \mathrm{~min}$ to inactivate the catalytic activity or in the presence of polymyxin B $(1 \mu \mathrm{g} / \mathrm{ml})$ to exclude any contribution of contaminating LPS in macrophage stimulation. As a control, pancreatic trypsin (Sigma-Aldrich Canada Ltd.) was used in the same range of concentrations $(0.00033$ to $33 \mu \mathrm{g} / \mathrm{ml}$ ). Lastly, PMA-differentiated U937 macrophages were also stimulated with S. suis P1/7 and G6G cells at a multiplicity of infection (MOI) of 100. All treatments were carried out for $18 \mathrm{~h}$ in a $5 \% \mathrm{CO}_{2}$ atmosphere.

\section{Determination of macrophage viability}

Following treatments with either the recombinant SspA or bacterial cells, cell viability was evaluated with an MTT (3-[4,5-diethylthiazol-2-yl]-2,5-diphenyltetrazolium bromide) test performed according to the manufacturer's protocol (Roche Diagnostics, Mannheim, Germany).

\section{Determination of cytokine secretion}

Commercial enzyme-linked immunosorbent assay (ELISA) kits (R\&D Systems, Minneapolis, MN, USA) were used to quantify IL-1 $\beta$, IL-6, TNF- $\alpha$, CCL5, and CXCL8 concentrations in the cell-free culture supernatants according to the manufacturer's protocols. The absorbance at $450 \mathrm{~nm}$ was read using a microplate 
reader with the wavelength correction set at $550 \mathrm{~nm}$. The rated sensitivities of the commercial ELISA kits were $3.9 \mathrm{pg} / \mathrm{ml}$ for IL-1 $\beta, 9.3 \mathrm{pg} / \mathrm{ml}$ for IL-6, $15.6 \mathrm{pg} / \mathrm{ml}$ for TNF- $\alpha$ and CCL5, and $31.2 \mathrm{pg} / \mathrm{ml}$ for CXCL8.

\section{Determination of cytokine degradation}

Degradation of IL-6, CXCL8, and CCL5 by the recombinant SspA was assessed by ELISA. Briefly, recombinant cytokines $(300 \mathrm{pg} / \mathrm{ml}$ of IL- $6,250 \mathrm{pg} / \mathrm{ml}$ of CXCL8, or $500 \mathrm{pg} / \mathrm{ml}$ of CCL5,) were incubated with the recombinant SspA at concentrations ranging from 0.26 to 16.5 $\mu \mathrm{g} / \mathrm{ml}$ for $4 \mathrm{~h}$. Following incubation, residual cytokines were quantified by ELISA as described above.

\section{Effect of kinase inhibitors on cytokine secretion}

Specific kinase inhibitors (Calbiochem, Mississauga, ON, Canada) used at the optimal concentration recommended by the manufacturer $(0.0625 \mu \mathrm{M})$ were added to macrophages $2 \mathrm{~h}$ prior to being treated with the recombinant SspA $(0.33 \mu \mathrm{g} / \mathrm{ml})$ for $18 \mathrm{~h}$. The inhibitors SB203580 [p38 mitogen-activated kinase (p38MAPK) inhibitor], UO126 [mitogen-activated extracellular kinase 1, 2 (MEK 1,2) inhibitor] and JNK inhibitor II [c-JUN N-terminal kinase (JNK) inhibitor], were evaluated for their effect on IL-6, CXCL8, and CCL5 secretion by macrophages.

\section{Statistical analysis}

All treatments and cytokine determination were performed in triplicate and the means \pm standard derivations were calculated. Differences were analyzed for statistical significance using the Student's t-test and were considered significant at $\mathrm{P}<0.01$.

\section{Results}

Prior to determine the capacity of the recombinant SspA of S. suis to induce an inflammatory response in PMAdifferentiated U937 macrophages, its effect on cell viability was evaluated. The MTT test revealed that macrophage viability was not significantly reduced (less than $20 \%$ ) by a treatment with the recombinant SspA at a concentration of up to $33 \mu \mathrm{g} / \mathrm{ml}$. As reported in Figure $1 \mathrm{~A}-\mathrm{C}$, a significant dose-dependent secretion of all three pro-inflammatory cytokines IL- $1 \beta$, IL- 6 and TNF- $\alpha$ was observed following stimulation of macrophages with the recombinant SspA. More specifically, treatment of macrophages with $S$ spA at $0.33 \mu \mathrm{g} / \mathrm{ml}$ resulted in a 2fold, 55-fold and 7-fold increase of IL-1 $\beta$, IL- 6 and TNF- $\alpha$ levels, respectively. In addition, there was a significant dose-dependent increase of CXCL8 and CCL5 secretion by macrophages stimulated with the recombinant SspA. The levels of CXCL8 (Figure 1D) increased by 17 -fold while that of CCL 5 (Figure 1E) increased by 15 -fold when the recombinant SspA was used at 0.33 $\mu \mathrm{g} / \mathrm{ml}$ (Figure 1D-E). In contrast, when the macrophages were stimulated with pancreatic trypsin instead of recombinant SspA, no increase in cytokine secretion was observed (Figure 1). When macrophages were stimulated with the recombinant SspA at the highest concentration $(33 \mu \mathrm{g} / \mathrm{ml})$, a very low amount of CCL5, which correspond to that of non-stimulated macrophages was detected. This decrease in cytokine production was also observed for IL-6 but to a much lesser extent (Figure 1B).

The effect of stimulating macrophages with heat-inactivated recombinant SspA or with active SspA in the presence of polymyxin (LPS neutralizing molecule) on the secretion of IL-6, CXCL8 and CCL5, the three cytokines produced in higher amounts by macrophages, was then tested. As reported in Table 1, the secretion of IL6 and CXCL8 was significantly increased after stimulation of macrophages with the active recombinant SspA $(33 \mu \mathrm{g} / \mathrm{ml})$ while only a slight increase was observed in the case of CCL5. The amounts of IL- 6 and CXCL8 produced by macrophages were not markedly different when the recombinant SspA of S. suis was inactivated by heat treatment $\left(30 \mathrm{~min}\right.$ at $\left.100^{\circ} \mathrm{C}\right)$. However, stimulation of macrophages with the heat-inactivated SspA was associated with a significantly higher amount of CCL5 in the conditioned culture medium compared to the treatment with the active recombinant SspA (72409 \pm 848 versus $2370 \pm 61 \mathrm{pg} / \mathrm{ml}$ ). Lastly, the presence of polymyxin B during stimulation of macrophages with the recombinant SspA protease had no significant effect on the levels of cytokine produced. The efficacy of polymyxin $B(1 \mu \mathrm{g} / \mathrm{ml})$ in neutralizing the inflammatory activity of Escherichia coli LPS was demonstrated in preliminary assays.

To further support the inflammatory property of the recombinant SspA, we compared the SspA-deficient mutant G6G and the parental strain for their capacity to induce of IL-1 $\beta$, TNF- $\alpha$, IL-6, CXCL8 and CCL5 secretion in macrophages. The MTT test revealed that macrophage viability was not significantly reduced (less than $10 \%$ ) by a treatment with cells of S. suis P1/7 or G6G at MOI of 100. As reported in Table 2, the amounts of IL- $1 \beta$, TNF- $\alpha$ and IL- 6 secreted by macrophages were significantly lower for the SspA-deficient mutant compared to the parental strain. More specifically, IL-1 $\beta$, TNF- $\alpha$ and IL- 6 production were decreased by $26 \%, 43 \%$ and $41 \%$, respectively. In contrast, the amounts of CCL5 5 and to a lesser extent CXCL8 were significantly higher when macrophages were stimulated with SspA-deficient mutant (G6G) compared to the parental strain.

Lastly we investigated the capacity of the SspA protease to degrade CCL5, IL-6 and CXCL8, the tree cytokines produced in higher amounts by macrophages 

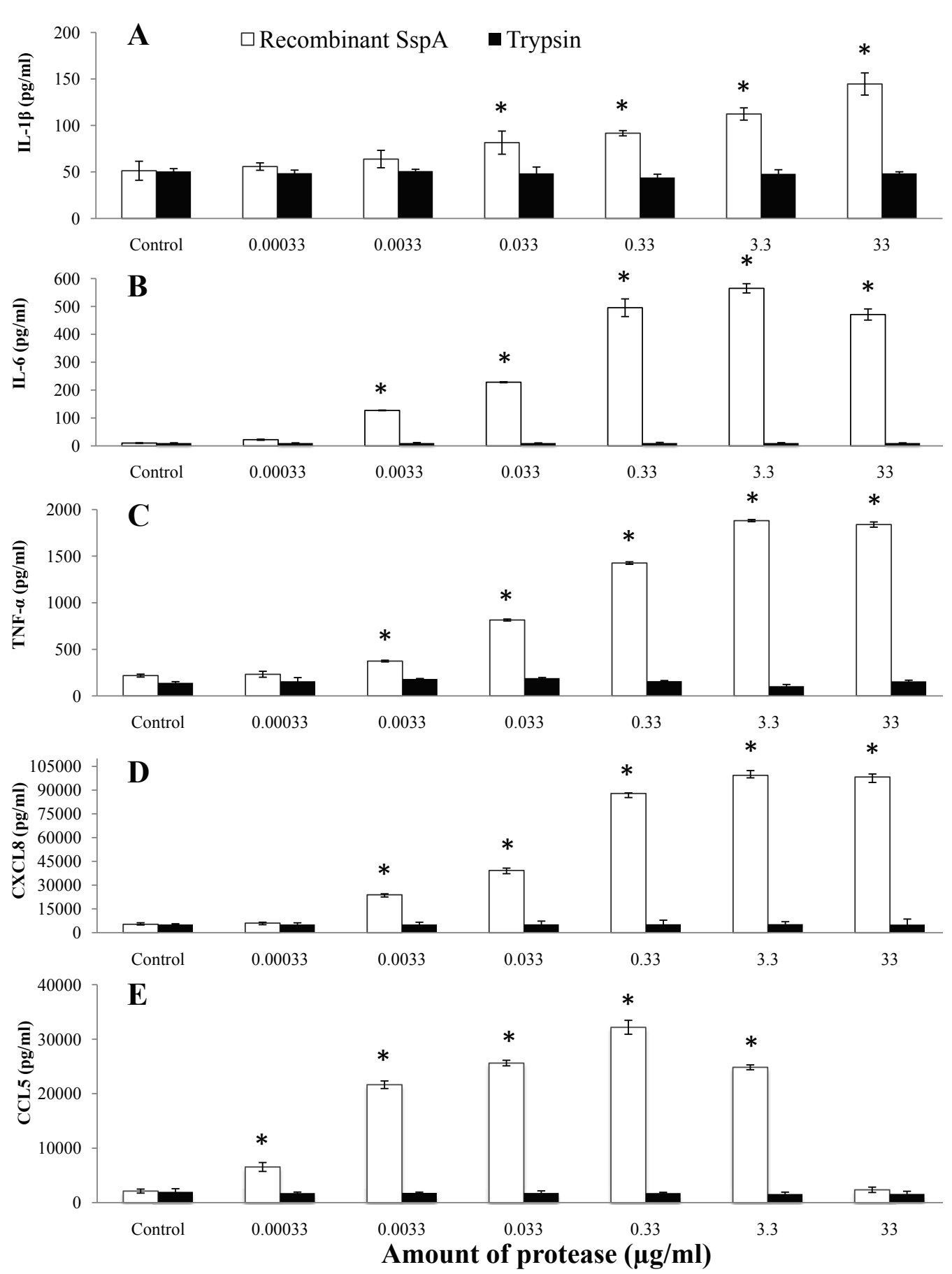

Figure 1 Cytokine secretion by PMA-differentiated U937 macrophages stimulated with the recombinant SspA of S. suis or with pancreatic trypsin. Following stimulation (18 h) with various amounts of proteases, the secretion of IL-1 $\beta$ (panel A), IL-6 (panel B), TNF- $\alpha$ (panel C), CXCL8 (panel D) and CCL5 (panel E) was assessed by ELISA. The data are the means \pm SD of triplicate assays from three separate experiments. Asterisks indicate a significant difference in comparison with the non-stimulated macrophages at $\mathrm{P}<0.01$.

stimulated with the recombinant SspA. Recombinant cytokines were incubated with the SspA protease at concentrations ranging from 0.26 to $16.5 \mu \mathrm{g} / \mathrm{ml}$ and after $4 \mathrm{~h}$, residual cytokines were determined by ELISA (Figure 2). There was a significant decrease in amounts of CCL5 in presence of SspA, even at low concentrations $(0.26 \mu \mathrm{g} / \mathrm{ml})$. Moreover, a decrease of approximately $20 \%$ was also noticed for IL-6 treated with SspA at $16.5 \mu \mathrm{g} / \mathrm{ml}$. In contrast, there was no decrease for CXCL8 following incubation with SspA. 
Table 1 Effect of heat treatment or the presence of polymyxin B on cytokine secretion by PMA-differentiated U937 macrophages stimulated with the recombinant SspA $(33 \mu \mathrm{g} / \mathrm{ml})$ of S. suis

\begin{tabular}{llll}
\hline Conditions & & \multicolumn{2}{c}{ Amount secreted (pg/ml) } \\
& CCL5 & IL-6 & CXCL8 \\
\hline Control (no stimulation) & $2081 \pm 14$ & $100 \pm 1$ & $3170 \pm 9$ \\
Recombinant SspA of S. suis & $2370 \pm 61^{*}$ & $1922 \pm 31^{*}$ & $108557 \pm 620^{*}$ \\
Heat-inactivated recombinant SspA of S. suis & $72409 \pm 848^{*}$ & $2111 \pm 71^{*}$ & $102287 \pm 1062^{*}$ \\
Recombinant SspA of S. suis + polymyxin B & $2081 \pm 32$ & $2099 \pm 254^{*}$ & $107446 \pm 590^{*}$ \\
\hline
\end{tabular}

The data are the means \pm SD of triplicate assays for three separate experiments. Asterisks indicate a significant difference in comparison with the unstimulated control at $\mathrm{P}<0.01$.

Thereafter, in order to identify the mechanism by which the recombinant SspA may activate macrophages, the effect of selected kinase inhibitors on the secretion of IL-6, CXCL8 and CCL5 by macrophages was investigated. As reported in Figure 3, a complete inhibition of CCL5 and CXCL8 secretion was observed in the presence of SB203580, an inhibitor specific to p38 mitogenactivated kinase (p38 MAPK). The secretion of IL- 6 by this kinase inhibitor was decreased by $28 \%$ while it was decreased by $85 \%$ with the JNK inhibitor.

\section{Discussion}

S. suis is a swine pathogen responsible for several infections including meningitidis, endocarditis and septicemiae, and is also an important agent for zoonosis [1]. Recently, a subtilisin-like protease, named SspA, was identified as a virulence factor in S. suis. This was based on the fact that SspA deficient mutants were significantly less pathogenic in animal models $[16,17]$. In the present study, we sought to determine the capacity of $S$. suis SspA to induce an inflammatory response in U937 macrophages.

We showed that recombinant SspA induced the secretion of IL- $1 \beta$, TNF- $\alpha$, IL- 6 , CXCL 8 and CCL 5 by macrophages. This significant cytokine secretion may be of utmost importance in S. suis-induced meningitis. Indeed, Lopes-Cortes et al., demonstrated that IL- $1 \beta$ and TNF- $\alpha$ are present in the cerebrospinal fluid and that high levels of these cytokines correlate with the neurological complications [25]. More specifically, IL1- $\beta$ can enhance the permeability of the blood-brain barrier [26]. Moreover, high levels in local body fluids and in serum of IL- 6 and TNF- $\alpha$ are associated with a fatal outcome [27]. Moller et al., also reported that the cerebrospinal fluid of patients suffering from bacterial meningitis contains much higher levels of chemokines, including CXCL8 [28].

To ensure that cytokine secretion by SspA-stimulated macrophages did not result from LPS contaminants, polymyxin B, an LPS-reacting molecule [29], was included durind stimulation. Results showed that polymyxin B, did not inhibit cytokine secretion thus suggesting that this stimulation is induced by the recombinant SspA protease only. This ability of the recombinant SspA to induced cytokine secretion in macrophages was found to be highly specific since it was not observed with the pancreatic trypsin used as a control.

Proteases can induce the secretion of inflammatory mediators in mammalian cells by two ways: action on proteinase-activated receptors (PARs) or through a nonproteolytic mechanism, involving the mitogen-activated protein kinases (MAPK) [30,31]. Several proteases have been identified as signaling molecules that specifically regulate members of PARs, a family of seven transmembrane domains G-protein-coupled receptors [32,33]. This family includes four members: PAR-1, PAR-3 and PAR-4 are receptors for thrombin, trypsin or cathepsin G, while PAR-2 is resistant to thrombin, but can be activated by trypsin, mast cell tryptase [30,34-36]. Since the heat-inactivated SspA still possessed the capacity to induce cytokine secretion in macrophages, the involvement of PARs could be ruled out. We thus investigated whether the SspA may induce cytokine secretion through activation of MAP kinases. More specifically, there are three major groups of MAPK in mammalian cells: the extracellular signal-regulated protein kinase

Table 2 Cytokine secretion by PMA-differentiated U937 macrophages following stimulation with S. suis P1/7 and its SspA deficient mutant G6G

\begin{tabular}{|c|c|c|c|c|c|}
\hline \multirow[t]{2}{*}{ Strain } & \multicolumn{5}{|c|}{ Amount secreted of cytokines $(\mathrm{pg} / \mathrm{ml})$} \\
\hline & IL-1 $\beta$ & TNF- $\alpha$ & IL-6 & CXCL8 & CCL5 \\
\hline Control & $51 \pm 3$ & $217 \pm 2$ & $10 \pm 1$ & $5245 \pm 432$ & $2116 \pm 4$ \\
\hline S. suis $\mathrm{P} 1 / 7$ & $161 \pm 8$ & $1800 \pm 11$ & $1160 \pm 21$ & $611000 \pm 756$ & $13355 \pm 564$ \\
\hline S. suis $\mathrm{G} 6 \mathrm{G}$ & $120 \pm 3^{*}$ & $1030 \pm 14^{*}$ & $690 \pm 6^{*}$ & $653000 \pm 634^{*}$ & $15664 \pm 34^{*}$ \\
\hline
\end{tabular}

The data are the means \pm SD of triplicate assays for three separate experiments. Asterisks indicate a significant difference in cytokine secretion by macrophages stimulated with the SspA deficient mutant $(\mathrm{G} 6 \mathrm{G})$ in comparison with the parental strain at $\mathrm{P}<0.01$. 


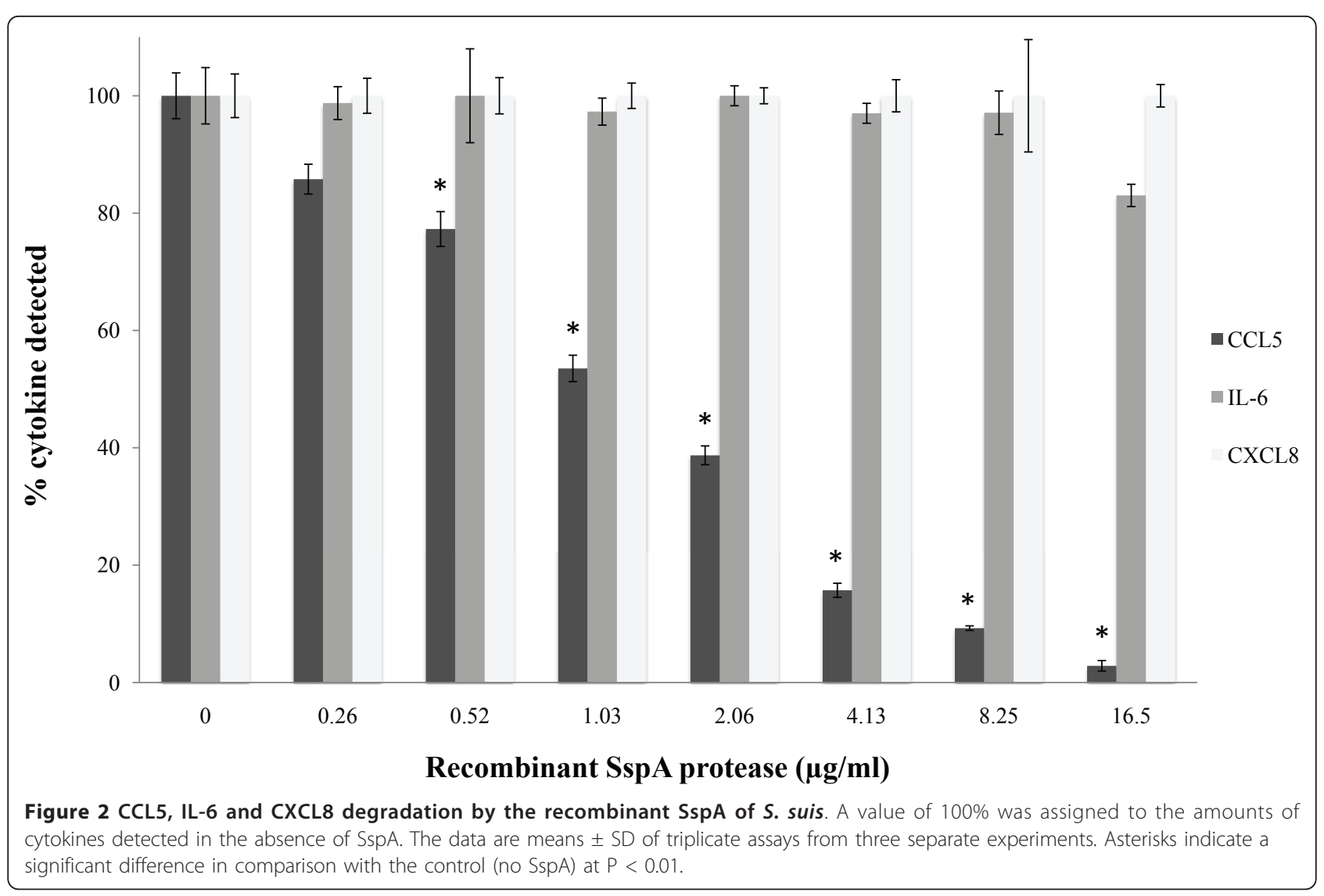

(ERK), the p38 MAPK and the c-Jun NH2-terminal kinase (JNK) [31]. Our results obtained by including kinase inhibitor during stimulation of macrophages with the recombinant SspA suggested that the production of CCL5 and CXCL8 was regulated by p38 MAPK while the production of IL- 6 was mostly regulated by JNK. MAPK are known as key regulators for the synthesis of numerous cytokines, chemokines, and other inflammatory mediators [31]. Previous studies also suggested a similar involvement of the MAPK regulatory pathway in inflammatory responses induced by S. suis [37-39]. In agreement with our observations, the cysteine proteinases of Porphyromonas gingivalis was also reported to use the MAPK transduction pathway to induce cytokine secretion in macrophages [40] and fibroblasts [41].

Our data showed that the amounts of CCL5 in the conditioned medium of macrophages stimulated with the heat-inactivated recombinant SspA was higher compared to that detected following stimulation with the active SspA. This suggests that SspA may degrade this cytokine. Using ELISA, we clearly showed the capacity of the recombinant SspA to degrade dose-dependently CCL5. Since CCL5 possesses chemotactic activity for immune cells, its inactivation by the SspA may allow S. suis to avoid and delay neutrophil attraction and activation. Cytokine degradation by proteases is a phenomenon well described in group A streptococci. Sumby et al., reported the ability of Streptococcus pyogenes SpyCEP to reduce neutrophil activity though cleavage and inactivation of the human chemokine granulocyte chemotactic protein 2 (GCP-2) [42]. In addition, the protease of $S$. pyogenes was reported to cleave CXCL8 $[42,43]$. Moreover, Bryan et al., showed that Streptococcus agalactiae CspA, inactivates the CXC chemokines GRO-alpha, GRO-beta, GRO-gamma, neutrophil-activating peptide 2 (NAP-2), and GCP-2 [44]. Lastly, the subtilisinlike protease SufA of Finegoldia magna, that shares many properties with the SspA of $S$. suis, has been shown to degrade the chemokine MIG/CXCL9 [45]. Degradation of CXCL8 by $S$. suis has been previously reported [46]. The protease involved in the cleavage of CXCL8 was different from the cell wall-anchored SspA since it was found to be secreted by S. suis [46].

The ability of SspA to induce cytokine secretion in macrophages was confirmed using a mutant of S. suis deficient in SspA expression. The secretion of IL-1 $\beta$, TNF- $\alpha$, and IL- 6 was significantly less important when macrophages were stimulated with cells of SspA mutant compared to the stimulation with the parental strain. This strongly supports the contribution of SspA in S. suis induced inflammatory response in macrophages. 


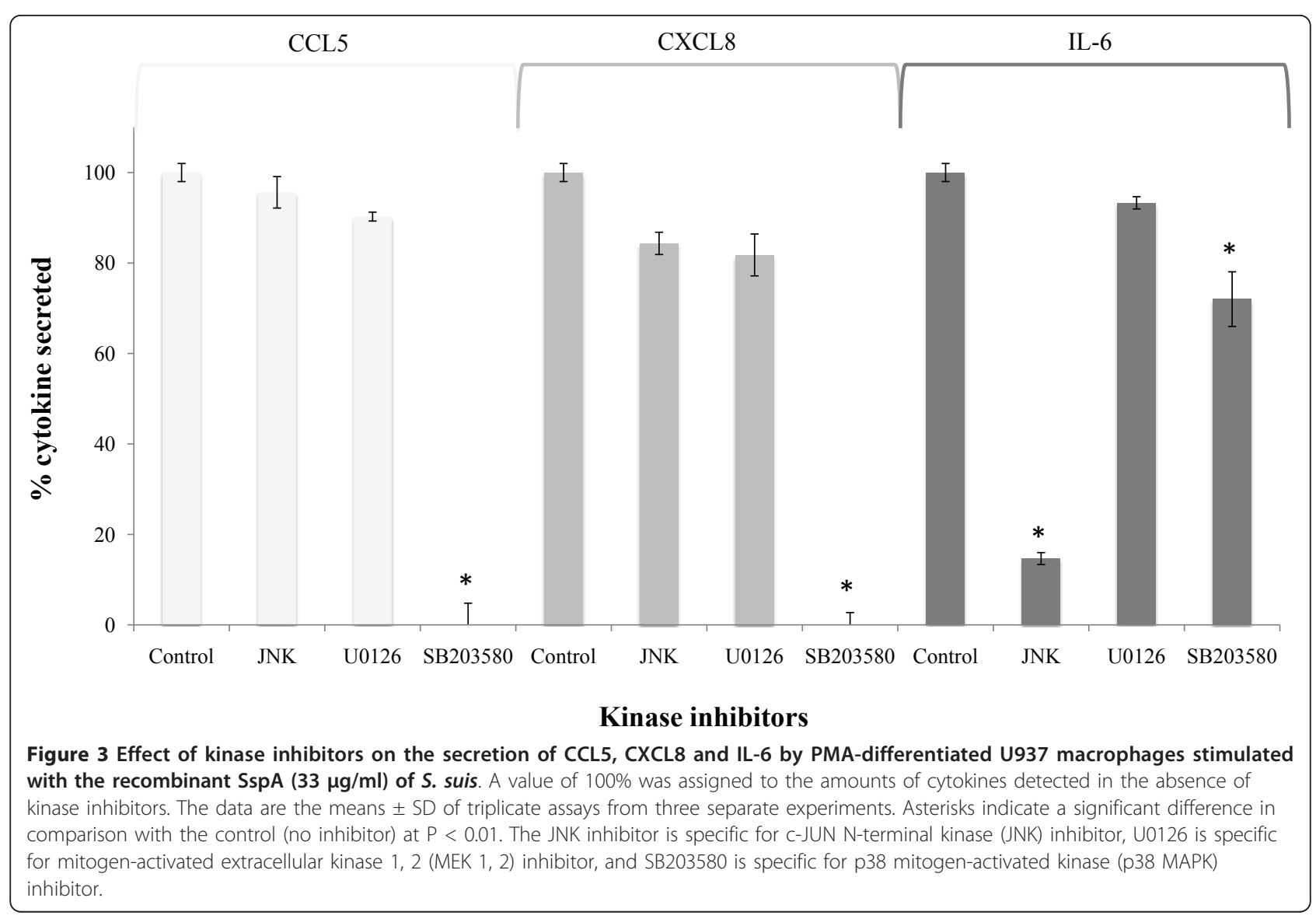

On the other hand, CCL5 secretion was found to be higher following stimulation with the SspA-deficient mutant compared to the parental strain. This result supports the capacity of the recombinant SspA protease to degrade CCL5. The fact that no decrease in CXCL8 secretion was observed following stimulation of macrophages with the SspA-deficient mutant suggests that other cell surface components of S. suis, such as the cell wall [46], are likely to play a more important role in CXCL8 secretion than the SspA protease.

\section{Conclusions}

In conclusion, this study bought evidence that the subtilisin-like protease SspA of S. suis may modulate the inflammation state associated with meningitis. It may either induce the secretion of important pro-inflammatory cytokines or, when present at high concentration, cause the degradation of selected cytokines, such as CCL5 and IL-6.

\section{Acknowledgements}

This study was supported by a grant from the Natural Sciences and Engineering Research Council of Canada (NSERC). We wish to thank K. Vaillancourt for her technical assistance and M. Gottschalk for helpful discussions.

\section{Author details}

${ }^{1}$ Groupe de Recherche en Écologie Buccale (GREB), Faculté de médecine dentaire, Université Laval, Quebec City, Quebec, Canada. ${ }^{2}$ Centre de Recherche en Infectiologie Porcine (CRIP), Fonds Québécois de la Recherche sur la Nature et les Technologies (FQRNT), Quebec, Canada.

\section{Authors' contributions}

LB performed all the experimental work and prepared the first draft of the manuscript. DG conceived the study design and prepared the final version of the manuscript. All authors read and approved the final manuscript.

Received: 6 December 2010 Accepted: 1 March 2011 Published: 1 March 2011

\section{References}

1. Higgins R, Gottschalk M: Diseases of swine. Streptococal diseases 2006, 769-783.

2. Huang YT, Teng LJ, Ho SW, Hsueh PR: Streptococcus suis infection. I Microbiol Immunol Infect 2005, 38(5):306-313.

3. Wertheim HF, Nghia HD, Taylor W, Schultsz C: Streptococcus suis: an emerging human pathogen. Clin Infect Dis 2009, 48(5):617-625.

4. Gottschalk M, Xu J, Lecours MP, Grenier D, Fittipaldi N, Segura M: Streptococcus suis Infections in Humans: What is the prognosis for Western countries? (Part I). Clinical Microbiology Newsletter 2010, 32(12):89-96.

5. Gottschalk M, Kobisch M, Berthelot-Herault F: L'infection à Streptococcus suis chez le porc: revue générale. Journées Rech Porcine en France 2001, 33:269-276.

6. Zhang C, Ning Y, Zhang Z, Song L, Qiu H, Gao H: In vitro antimicrobial susceptibility of Streptococcus suis strains isolated from clinically healthy sows in China. Vet Microbiol 2008, 131(3-4):386-392. 
7. Tian Y, Aarestrup FM, Lu CP: Characterization of Streptococcus suis serotype 7 isolates from diseased pigs in Denmark. Vet Microbiol 2004, 103(1-2):55-62

8. Costa AT, Lobato FC, Abreu VL, Assis RA, Reis R, Uzal FA: Serotyping and evaluation of the virulence in mice of Streptococcus suis strains isolated from diseased pigs. Rev Inst Med Trop Sao Paulo 2005, 47(2):113-115.

9. Smith HE, Damman M, van der Velde J, Wagenaar F, Wisselink HJ, Stockhofe-Zurwieden N, Smits MA: Identification and characterization of the cps locus of Streptococcus suis serotype 2: the capsule protects against phagocytosis and is an important virulence factor. Infect Immun 1999, 67(4):1750-1756.

10. Jacobs AA, Loeffen PL, van den Berg AJ, Storm PK: Identification, purification, and characterization of a thiol-activated hemolysin (suilysin) of Streptococcus suis. Infect Immun 1994, 62(5):1742-1748.

11. de Greeff A, Buys H, Verhaar R, Dijkstra J, van Alphen L, Smith HE: Contribution of fibronectin-binding protein to pathogenesis of Streptococcus suis serotype 2. Infect Immun 2002, 70(3):1319-1325.

12. Esgleas M, Li Y, Hancock MA, Harel J, Dubreuil JD, Gottschalk M: Isolation and characterization of alpha-enolase, a novel fibronectin-binding protein from Streptococcus suis. Microbiology 2008, 154(Pt 9):2668-2679.

13. Jobin MC, Grenier D: Identification and characterization of four proteases produced by Streptococcus suis. FEMS Microbiol Lett 2003, 220(1):113-119.

14. Jobin MC, Martinez G, Motard J, Gottschalk M, Grenier D: Cloning purification, and enzymatic properties of dipeptidyl peptidase IV from the swine pathogen Streptococcus suis. J Bacteriol 2005, 187(2):795-799.

15. Bonifait L, Vaillancourt K, Gottschalk M, Frenette M, Grenier D: Purification and characterization of the subtilisin-like protease of Streptococcus suis that contributes to its virulence. Vet Microbiol 2010.

16. Bonifait $L$, de la Cruz Dominguez-Punaro M, Vaillancourt K, Bart C, Slater J, Frenette M, Gottschalk M, Grenier D: The cell envelope subtilisin-like proteinase is a virulence determinant for Streptococcus suis. BMC Microbiol 2010, 10:42

17. Hu Q, Liu P, Yu Z, Zhao G, Li J, Teng L, Zhou M, Bei W, Chen H, Jin M: Identification of a cell wall-associated subtilisin-like serine protease involved in the pathogenesis of Streptococcus suis serotype 2. Microb Pathog 2009, 48(3-4):103-109.

18. Gottschalk M, Segura M: The pathogenesis of the meningitis caused by Streptococcus suis: the unresolved questions. Vet Microbiol 2000, 76(3):259-272.

19. Segura M, Vadeboncoeur N, Gottschalk M: CD14-dependent and -independent cytokine and chemokine production by human THP-1 monocytes stimulated by Streptococcus suis capsular type 2. Clin Exp Immunol 2002, 127(2):243-254.

20. Vadeboncoeur N, Segura M, Al-Numani D, Vanier G, Gottschalk M: Proinflammatory cytokine and chemokine release by human brain microvascular endothelial cells stimulated by Streptococcus suis serotype 2. FEMS Immunol Med Microbiol 2003, 35(1):49-58.

21. Tanabe S, Grenier D: Endothelial cell/macrophage cocultures as a model to study Streptococcus suis-induced inflammatory responses. FEMS Immunol Med Microbiol 2009, 55(1):100-106.

22. Dominguez-Punaro MC, Segura M, Plante MM, Lacouture S, Rivest S, Gottschalk M: Streptococcus suis serotype 2, an important swine and human pathogen, induces strong systemic and cerebral inflammatory responses in a mouse model of infection. J Immunol 2007 179(3):1842-1854.

23. Van Furth A, Roord J, Van Furth R: Roles of proinflammatory and antiinflammatory cytokines in pathophysiology of bacterial meningitis and effect of adjunctive therapy. Infect Immun 1996, 64(12):4883-4890.

24. Rovera G, Santoli D, Damsky C: Human promyelocytic leukemia cells in culture differentiate into macrophage-like cells when treated with a phorbol diester. Proc Natl Acad Sci USA 1979, 76(6):2779-2783.

25. Lopez-Cortes LF, Cruz-Ruiz M, Gomez-Mateos J, Jimenez-Hernandez D, Palomino J, Jimenez E: Measurement of levels of tumor necrosis factoralpha and interleukin-1 beta in the CSF of patients with meningitis of different etiologies: utility in the differential diagnosis. Clin Infect Dis 1993, 16(4):534-539.

26. Quagliarello VJ, Wispelwey B, Long WJ Jr, Scheld WM: Recombinant human interleukin-1 induces meningitis and blood-brain barrier injury in the rat. Characterization and comparison with tumor necrosis factor. J Clin Invest 1991, 87(4):1360-1366.
27. Helfgott DC, Tatter SB, Santhanam U, Clarick RH, Bhardwaj N, May LT, Sehgal PB: Multiple forms of IFN-beta $2 / \mathrm{IL}-6$ in serum and body fluids during acute bacterial infection. J Immunol 1989, 142(3):948-953.

28. Moller AS, Bjerre A, Brusletto B, Joo GB, Brandtzaeg P, Kierulf P: Chemokine patterns in meningococcal disease. J Infect Dis 2005, 191(5):768-775.

29. Morrison DC, Jacobs DM: Binding of polymyxin B to the lipid A portion of bacterial lipopolysaccharides. Immunochemistry 1976, 13(10):813-818.

30. Dery O, Corvera CU, Steinhoff M, Bunnett NW: Proteinase-activated receptors: novel mechanisms of signaling by serine proteases. Am J Physiol 1998, 274(6 Pt 1):C1429-1452.

31. Dong C, Davis RJ, Flavell RA: MAP kinases in the immune response. Annu Rev Immunol 2002, 20:55-72.

32. Macfarlane SR, Seatter MJ, Kanke T, Hunter GD, Plevin R: Proteinaseactivated receptors. Pharmacol Rev 2001, 53(2):245-282.

33. Hollenberg MD, Compton SJ: International Union of Pharmacology. XXVIII. Proteinase-activated receptors. Pharmacol Rev 2002, 54(2):203-217.

34. Xu WF, Andersen H, Whitmore TE, Presnell SR, Yee DP, Ching A, Gilbert T, Davie EW, Foster DC: Cloning and characterization of human proteaseactivated receptor 4. Proc Natl Acad Sci USA 1998, 95(12):6642-6646.

35. Steinhoff M, Buddenkotte J, Shpacovitch V, Rattenholl A, Moormann C, Vergnolle N, Luger TA, Hollenberg MD: Proteinase-activated receptors: transducers of proteinase-mediated signaling in inflammation and immune response. Endocr Rev 2005, 26(1):1-43.

36. Vu TK, Hung DT, Wheaton VI, Coughlin SR: Molecular cloning of a functional thrombin receptor reveals a novel proteolytic mechanism of receptor activation. Cell 1991, 64(6):1057-1068.

37. de Greeff A, Benga L, Wichgers Schreur PJ, Valentin-Weigand P, Rebel JM, Smith HE: Involvement of NF-kappaB and MAP-kinases in the transcriptional response of alveolar macrophages to Streptococcus suis. Vet Microbiol 2010, 141(1-2):59-67.

38. Jenner $R G$, Young RA: Insights into host responses against pathogens from transcriptional profiling. Nat Rev Microbiol 2005, 3(4):281-294.

39. Segura M, Vanier G, Al-Numani D, Lacouture S, Olivier M, Gottschalk M: Proinflammatory cytokine and chemokine modulation by Streptococcus suis in a whole-blood culture system. FEMS Immunol Med Microbiol 2006 47(1):92-106.

40. Grenier $D$, Tanabe $S$ : Porphyromonas gingivalis gingipains trigger a proinflammatory response in human monocyte derived macrophages through the p38 mitogen-activated protein kinase signal transduction pathway. Toxins 2010, 2:341-352.

41. Matsushita K, Imamura T, Tomikawa M, Tancharoen S, Tatsuyama S, Maruyama I: DX-9065a inhibits proinflammatory events induced by gingipains and factor Xa. J Periodontal Res 2006, 41(2):148-156.

42. Sumby P, Zhang S, Whitney AR, Falugi F, Grandi G, Graviss EA, Deleo FR, Musser JM: A chemokine-degrading extracellular protease made by group A Streptococcus alters pathogenesis by enhancing evasion of the innate immune response. Infect Immun 2008, 76(3):978-985.

43. Hidalgo-Grass C, Mishalian I, Dan-Goor M, Belotserkovsky I, Eran Y, Nizet V, Peled A, Hanski E: A streptococcal protease that degrades CXC chemokines and impairs bacterial clearance from infected tissues. $E M B O$ J 2006, 25(19):4628-4637

44. Bryan JD, Shelver DW: Streptococcus agalactiae CspA is a serine protease that inactivates chemokines. J Bacterio/ 2009, 191(6):1847-1854

45. Karlsson C, Eliasson M, Olin Al, Morgelin M, Karlsson A, Malmsten M, Egesten A, Frick IM: SufA of the opportunistic pathogen Finegoldia magna modulates actions of the antibacterial chemokine MIG/CXCL9, promoting bacterial survival during epithelial inflammation. J Biol Chem 2009, 284(43):29499-29508

46. Vanier G, Segura M, Lecours MP, Grenier D, Gottschalk M: Porcine brain microvascular endothelial cell-derived interleukin-8 is first induced and then degraded by Streptococcus suis. Microb Pathog 2009, 46(3):135-143.

doi:10.1186/1471-2180-11-47

Cite this article as: Bonifait and Grenier: The SspA subtilisin-like protease of Streptococcus suis triggers a pro-inflammatory response in macrophages through a non-proteolytic mechanism. BMC Microbiology 2011 11:47. 